\title{
Randomized control trial comparing primary hip spica versus initial traction and hip spica of fracture at or below the junction of the upper and middle third of femur in children
}

\author{
P Chaudhary ${ }^{1}$, AR Bajracharya ${ }^{2}$, A Joshi $^{2}$, B Sharma ${ }^{2}$, R Bose $^{2}$, BP Shrestha ${ }^{1}$, GP Khanal ${ }^{1}$ \\ Department of Orthopaedics ${ }^{1}$, B.P. Koirala Institute of Health Sciences, Dharan, Nepal ${ }^{1}$ \\ Department of Orthopaedics ${ }^{2}$, NAMS, Bir Hospital ${ }^{2}$
}

\begin{abstract}
Background: The debate regarding optimal management of femoral shaft fractures in the pediatric population is still far from resolved. While some consensus exists in the treatment of this injury in children younger than the age of six, opinion still widely divided in children six to 11 years. Objective: The aim of study was to compare the outcome of primary hip spica versus initial traction and hip spica of fracture of shaft of femur at or below the junction of the upper and middle third in children in terms of deformity and fracture healing. Method: A RCT study was carried out in the departments of Orthopedics, B.P.Koirala Institute of Health Sciences, Dharan, Nepal from March 2004 to January 2006. Forty five patients were included in the study in which 22 patients included in early spica casting (group I) and 23 patients in traction with spica casting (group II). The functional outcomes were assessed with Pearson' Chi-square test, Independent samples test and union was assessed radiologically. Result: There was no statistically significant difference in time of union; all of them united in 8-10 weeks follow up. No significant overall difference in terms of deformity was noted in the two groups( $p$ value-0.306). There was significant difference in terms of hospital stay in both the groups( $p$ value $<0.05)$. Conclusion: The study showed that there is significant advantage in primary hip spica cast for the treatment of isolated, closed femur fractures in children ages less than 10 years and weight less than 80 pounds $(45 \mathrm{~kg})$ which allowed us to treat these fractures without any worry of wound dehiscence, pin site infections, avascular necrosis of the femoral head.
\end{abstract}

Keywords: Hip spica, shaft of femur, traction

\footnotetext{
Address for correspondence

Dr. Pashupati Chaudhary

Associate Professor

Department of Orthopaedics

B.P. Koirala Institute of Health Sciences, Dharan

E-mail: chaudharypashupati@yahoo.com
} 


\section{Introduction}

Fractures of shaft of femur are common in children. ${ }^{1}$ femoral shaft fractures represent $1.6 \%$ of all pediatric fractures and $7.6 \%$ of all pediatric long bone fractures. ${ }^{2}$ Fractures of shaft of femur usually results from direct violence. Femoral fractures in younger children occurs due to low energy trauma e.g. simple falls, sport related activity. Whereas in older children due to high energy trauma e.g. road traffic accident. ${ }^{3}$

However, child abuse is commonest cause of femoral shaft fracture in children under 3-4 years of age. The incidence of child abuse approaches $80 \%$ in infants and $30 \%$ in children younger than 4 years of age. ${ }^{2}$

There is no formal classification system for femoral shaft fractures but it can be classified according to the geometry of major fracture line i.e. described as transverse, spiral, and oblique, segmental, comminuted. Femoral shaft fractures can be categorized geographically as proximal third, mid shaft or distal third. ${ }^{3}$

The debate regarding optimal management of femoral shaft fractures in the pediatric population is still far from resolved. While some consensus exists in the treatment of this injury in children younger than the age of six, opinion still widely divided in children six to 11 years. ${ }^{4}$

Fracture trends have not changed substantially but the emphasis on the use of some form of treatment has altered depending on the changing socio-economic and geographic condition of our region, some becoming popular, while others waning a little. Some treatments are not so universally accepted, while others have proven themselves. The popularity of treatment methods waxes and wanes. But there is one principle that always stands out as a clear guide-"We are here not to replace nature's methods of repair, but only to use the intelligence to assist that repair, and prevent some of the disabilities which can be the result if nature is left to its own resources."

This general philosophy has been taken to equate the widely diverging opinion on overall management of fracture of shaft of femur. Bone is vital, it lives and generates day by day; it grows and remodels and like any other lesions in the body, has its own built in methods of repair, which cannot be suppressed by anything that man can devise. All surgical endeavors has to be designed to assist this natural repair, but we know that nature can produce necessary "glue" to repair any tissue defects. In many cases function cannot be restored without the help of surgeons. ${ }^{5}$

The management of pediatric femoral shaft fractures depends on many factors including age, the mechanism of injury, fracture configuration, associated injuries, economic considerations and psychosocial issues i.e. 
presence of family support for home care, and emotional status of patient and parents all must be considered. The goal is to achieve bony union without excessive shortening or misalignment. ${ }^{2}$

In this study, the objective was to develop criteria for the prospective identification of patients who can be treated safely and dependably with early spica casting, an attempt is made to identify other variables that would be useful in prospectively identifying children at risk for unsatisfactory outcome, so that one can treat the majority of children with early spica casting successfully. Virtually, any method of treatment will be successful if success is defined by healing of the fracture and resumption of usual activities, because children are doomed to heal. $^{6}$

\section{Methods}

This was a prospective comparative study done in department of orthopedics, B.P. Koirala Institute of Health Sciences, Dharan. Total 22 patients in group I and 23 patients in group II were included in the study. The inclusion criteria were children aged 10 yrs or less, fracture at or below the junction of upper and middle $1 / 3$ of femur, closed fractures, children without other injuries e.g. head injury, transverse or oblique or spiral fracture, weight less than 80 pounds $(45 \mathrm{~kg})$ and the exclusion criteria were fracture of proximal femur, older children more than 10 years, children with severe multiple injuries, comminuted fracture, suspected child abuse, weight more than 80 0pounds (45kg).

A thorough history taking was done for every patient included in the study followed by a general systemic review. The involved thigh was examined locally for swelling open wound, tenderness, deformity. Radiographs of the thigh, antero posterior and lateral views are taken. All routine investigation was done to evaluate fitness for anesthesia. The patient's age and weight were also evaluated. Hip spica was applied on emergency and elective basis, if hip spica was not applied in emergency basis, the limb was immobilized in Thomas splint or skin traction.

\section{Hip sica application technique}

Under general anesthesia, Hip spica was applied in two parts. In first part, an assistant holds the ankle in one hand and the calf in the other hand and a long leg cast is applied with knee flexed 40-60degrees. The plaster being molded to correct angulations. Then the child is placed on hip spica table. When the plaster has set, longitudinal traction is applied to calf section of the cast to correct any shortening but no attempt is made to achieve an end to end reduction of the displaced fracture. Once the thigh portion of the cast hardened, long leg cast is extended into one and half for older children and 
double spica for infants. With hip flexed, so that heel and buttock are leveled. Wooden bar was placed between patients leg and incorporated into the cast to help the cast hold the legs and pelvis in correct position.

To facilitate the toilet use, bar was placed in front of the thighs for girls and back for boys. Careful four corner molding with antero posterior compression and mediolateral compression at the fracture side achieved proper fracture reduction and alignment.

Sagittal and frontal radiographs were taken.The perineal region of the cast was then trimmed. Rotation is judged clinically; the foot should be in slight lateral rotation. The plaster under the sole of the foot is removed so that plantar flexion against it cannot cause shortening, and the spica is then reinforced. The child was admitted to the hospital for 24 hours observation to ensure, they did not develop plaster complications. The child is allowed to return home the following day and the parents are shown how to care for the child. The child is reviewed one week after the injury. If radiographs are satisfactory, the child is then reviewed $2^{\text {nd }}$ and $3^{\text {rd }}$ weeks. During most of the period of the study, the patient (child) was examined in out-patient department. After the cast was applied, the children returned for follow up at 1month-6month, then annually until complications occurred.
If the fracture angulated within the first 2 weeks of reduction greater than acceptable degree, cast wedging was performed to correct angulation, if unacceptable shortening occurred within first 2 weeks, the cast was changed, the femur was reduced again and four corner molding was applied.

Timing to healing is difficult to measure accurately. The time until full weight bearing was considered the best measure of healing. Callus formation is the useful indicator of fracture healing. Callus formation was graded on a scale of 0-3. Grade 0 indicated, there was no identifiable fracture healing present. For grade 1, primary bone healing with little or no periosteal new bone formation was present. Grade 2 described periosteal new bone formation present on two sides of femur and in grade 3; periosteal new bone formation was present on three or four sides of femur. Callus formation for all of the fractures was graded at the time, full weight bearing was permitted.

Up to $2 \mathrm{~cm}$ of shortening, 20 degree of anterior angulation and 15 degrees of valgus angulation but no posterior angulation or varus was accepted. All hip spica was removed 6-8 weeks after injury with check coronal and sagittal radiographs and clinical examination confirming union.

All of the patients were discharged from hospital within 24 hours of the application of the spica cast. During that time plaster 
complications were checked. Radiographs were obtained to look for post spica deformity in terms of shortening, angulation, rotation.

Patients were discharged with advice to caregivers regarding maintenance of hygiene, care of plaster and its complications. Weekly follow up radiographs were taken for the first 3 weeks because fracture shortening and angulation most likely will occur during this period. If there was unacceptable angulation, it was corrected with wedging of cast.

The first follow up were scheduled on first week of spica application and patients were assessed for deformities (shortening, angulation, rotation) and plaster complications. Second follow up at second week and patients were evaluated for deformities (angulation, rotation, shortening), complication due to spica (local pressure, breakage of spica) and also evaluation of $\mathrm{x}$ ray femur-AP, LATERAL were done. The third follow up was done at third week, fourth at $6^{\text {th }}$ week and fifth at $12^{\text {th }}$ week. Evaluation of $\mathrm{x}$-ray for fracture healing was done.

\section{Results}

The total number of patients included in this study was 45 , who were treated from March 2004 to January 2006 in department of orthopedics in National Academy of Medical Sciences, Bir Hospital, Patan Hospital, Shree Birendra Hospital, Kathmandu. There were 29 males and 16 females. Twenty two patients were included in group I with a male to female ratio of $2.1: 1$ and 23 patients in group II with a male to female ratio of 1.5:1.

The age ranges from 9 months to 10 years with mean age of 46.77 months in group I and 57.78 months in group II. The weight ranges from $7-25 \mathrm{~kg}$ with mean weight of $14.5 \mathrm{~kg}$ in group I and $15.6 \mathrm{~kg}$ in group II. Table 1 shows age distribution with weight.

Table 1: Distribution of the patients according to age, weight

\begin{tabular}{|l|l|l|l|l|l|}
\hline & Group of study & N & Mean & \multicolumn{1}{|c|}{$\begin{array}{c}\text { Std. } \\
\text { deviation }\end{array}$} & P value \\
\hline Age of the patient in month & Group I & 22 & 46.77 & 30.294 & 0.176 \\
\cline { 2 - 5 } & Group II & 23 & 57.78 & 23.065 & \\
\hline Weight of the patient in $\mathrm{kg}$ & Group I & 22 & 14.5000 & 4.20600 & \multirow{2}{*}{7.00} \\
\cline { 2 - 5 } & Group II & 23 & 15.6957 & 3.49590 & \\
\hline
\end{tabular}

The Measurements and hospital stay are shown in Table 2. The shortening of fractured limb after removal of hip spica was $1.21 \mathrm{~cm}$ in group I and 1.26 in group II. The thigh muscle wasting was $1.14 \mathrm{~cm}$ in group I and 1.02 in group II. The mean days of hospital stay in 
group I was 2.36days and 13.04days in group

II. The hip spica was applied within 1.76 days of injury in group I and within 13.09days of injury in group II.

Table 2: Distribution of Measurements, hospital stay and application of hip spica

\begin{tabular}{|c|c|c|c|c|c|}
\hline & Group of study & $\mathbf{N}$ & Mean & $\begin{array}{c}\text { Std. } \\
\text { deviation }\end{array}$ & $P$ value \\
\hline \multirow[t]{2}{*}{ Shortening of limb } & Group I & 14 & 1.2143 & .46881 & \multirow{2}{*}{0.898} \\
\hline & Group II & 17 & 1.2353 & .43724 & \\
\hline \multirow[t]{2}{*}{ Thigh muscle wasting } & Group I & 21 & 1.1429 & .39188 & \multirow{2}{*}{0.354} \\
\hline & Group II & 20 & 1.0250 & .41279 & \\
\hline \multirow[t]{2}{*}{ Hospital stay in days } & Group I & 14 & 2.36 & 1.598 & \multirow{2}{*}{0.000} \\
\hline & Group II & 23 & 13.04 & 3.994 & \\
\hline \multirow{2}{*}{$\begin{array}{l}\text { Hip spica within no. of } \\
\text { days of injury }\end{array}$} & Group I & 17 & 1.76 & 1.522 & \multirow{2}{*}{0.000} \\
\hline & Group II & 23 & 13.09 & 4.188 & \\
\hline \multirow[t]{2}{*}{ No. of traction days } & Group I & 0 & - & - & - \\
\hline & Group II & 23 & 12.26 & 3.805 & \\
\hline
\end{tabular}

Twenty-two patients were included in group I with male to female ratio of $2: 1$ and twentythree patients in group II with male to female ratio of $1.5: 1$. The side distribution was almost equal in both groups i.e. Right side was involved in 12 cases and left side involved in 10 cases in group I whereas 11 cases in right side and 12 cases in left side in group II. The spiral, oblique fracture was most frequent in group I whereas oblique, transverse fracture was most common in group II. The side distribution, pattern and mode of injury are shown in Table 3.

Table 3: Distribution of the patients according to sex, side, pattern and mode of injury

\begin{tabular}{|c|c|c|c|c|}
\hline \multirow[b]{2}{*}{ Sex of patient } & \multicolumn{2}{|c|}{ Group of study } & \multirow[b]{2}{*}{ Total } & \multirow[b]{2}{*}{$P$ value } \\
\hline & Group I & Group II & & \\
\hline Male & 15 & 14 & 29 & \multirow{3}{*}{0.608} \\
\hline Female & 7 & 9 & 16 & \\
\hline Total & 22 & 23 & 45 & \\
\hline Side of fracture & & & & \\
\hline
\end{tabular}




\begin{tabular}{|c|c|c|c|c|}
\hline Left & 12 & 12 & 24 & 0.873 \\
\hline Right & 10 & 11 & 21 & \\
\hline Total & 22 & 23 & 45 & \\
\hline \multicolumn{5}{|l|}{ Fracture pattern } \\
\hline Transverse & 4 & 6 & 10 & \multirow{4}{*}{0.377} \\
\hline Spiral & 9 & 5 & 14 & \\
\hline Oblique & 9 & 12 & 21 & \\
\hline Total & 22 & 23 & 45 & \\
\hline \multicolumn{5}{|l|}{ Mode of injury } \\
\hline Fall from height & 15 & 17 & 32 & \\
\hline Play Injury & 4 & 1 & 5 & \\
\hline RTA & 0 & 5 & 5 & \\
\hline Others & 3 & 0 & 3 & \\
\hline Total & 22 & 23 & 45 & \\
\hline \multicolumn{5}{|c|}{ Fracture location } \\
\hline Upper 3rd & 8 & 8 & 16 & \multirow{4}{*}{0.842} \\
\hline Middle 3 rd & 11 & 13 & 24 & \\
\hline Lower 3rd & 3 & 2 & 5 & \\
\hline Total & 22 & 23 & 45 & \\
\hline
\end{tabular}

The anterior angulation was 20 degrees in group I and 15 degrees in group II with mean angulation was 11.75 and 13.40 degrees respectively. The valgus angulation was 19 degrees in both the groups with mean 12.11 and 14.37 degrees respectively. There were no varus and posterior angulation. Distribution according to Deformity is shown in Table 4.

Table 4: Distribution of study group according to its deformity

\begin{tabular}{|l|l|c|l|l|l|}
\hline \multicolumn{1}{|c|}{$\begin{array}{c}\text { Angulation in } \\
\text { degrees }\end{array}$} & $\begin{array}{c}\text { Group of } \\
\text { study }\end{array}$ & $\mathbf{N}$ & Mean & $\begin{array}{c}\text { Std. } \\
\text { deviation }\end{array}$ & \multicolumn{1}{|c|}{ Std. error mean } \\
\hline Anterior angulation & Group I & 20 & 11.75 & 4.667 & 1.043 \\
\cline { 2 - 7 } & Group II & 15 & 13.40 & 4.405 & 1.137 \\
\hline Valgus angulation & Group I & 19 & 12.11 & 6.732 & 1.544 \\
\hline
\end{tabular}




\begin{tabular}{|c|c|c|c|c|c|}
\hline & Group II & 19 & 14.37 & 5.377 & 1.234 \\
\hline \multirow[t]{2}{*}{ Posterior angulation } & Group I & 0 (a) & . & . & \\
\hline & Group II & 0 (a) & . & . & . \\
\hline \multirow[t]{2}{*}{ Varus angulation } & Group I & 0 (a) & . & . & \\
\hline & Group II & $0(a)$ & . & . & . \\
\hline \multirow{2}{*}{$\begin{array}{l}\text { Rotation of fracture } \\
\text { fragment }\end{array}$} & Group I & 0 (a) & . & . & . \\
\hline & Group II & $0(\mathrm{a})$ & . & . & . \\
\hline
\end{tabular}

One and half hip spica was applied most commonly in both the groups irrespective of age of the patients and double spica in one case of group II (Table 5). The mean radiological union was evident at 9.27 weeks of follow up in group I and 8.78 weeks in group II ( $p$ value- 0.306$)$ (Table 6$)$

Table 5: Distribution of study groups according to type of hip spica

\begin{tabular}{|l|l|l|l|}
\hline \multirow{2}{*}{\multicolumn{1}{|c|}{ Type of spica }} & \multicolumn{2}{c|}{ Group of study } & \multirow{2}{*}{ Total } \\
\cline { 2 - 4 } & \multicolumn{2}{|c|}{ Group I } & \multicolumn{2}{c|}{ Group II } & \\
\hline One and half & 22 & 22 & 44 \\
\hline Double & 0 & 1 & 1 \\
\hline Total & 22 & 23 & 45 \\
\hline
\end{tabular}

Table 6: According to Radiological union

\begin{tabular}{|l|l|l|l|l|l|}
\hline \multirow{4}{*}{ Radiological union in weeks } & Group of study & N & Mean & Deviation & \multirow{2}{*}{ P value } \\
\cline { 2 - 6 } & Group I & 22 & 9.27 & 1.667 & 0.306 \\
\cline { 2 - 5 } & Group II & 23 & 8.78 & 1.506 & \\
\hline
\end{tabular}

The complication noted were breakage of hip spica in 9 cases, out of which 5 in group I and 4 in group II, which was treated, with reinforcing of plaster. The other complications were pressure sores in one cases of group I, unacceptable angulation in one cases of group I, which was corrected, with wedging of cast (Table 7) 
Table 7: Distribution of patients according to its complication

\begin{tabular}{|c|c|c|c|c|}
\hline \multirow{2}{*}{ Complications } & \multicolumn{2}{|c|}{ Group of study } & \multirow[b]{2}{*}{ Total } & \multirow{4}{*}{$P$ value } \\
\hline & Group I & Group II & & \\
\hline Breakage of plaster & 5 & 4 & 9 & \\
\hline Pressure sores & 0 & 1 & 1 & \\
\hline Angulation & 1 & 0 & 1 & 0.350 \\
\hline
\end{tabular}

\section{Discussion}

The management of pediatric femoral shaft fractures depends on many factors including age, the mechanism of injury, fracture configuration, associated injuries, and economic considerations and psychosocial issues i.e. presence of family support for home care, emotional status of patient and parents all must be considered. The goal is to achieve bony union without excessive shortening or misalignment ${ }^{9}$.

In this present study of 45 patients of which 22 patients underwent primary hip spica (group I) and 23 patients in traction followed by hip spica (group II). The age ranges from 9 months to 10 years with mean age in group 1 was 46.77 months and in group 2, 57.78 months. One and half hip spica was applied in children and for infants double hip spica was applied. There were 29 males and 16 females. There were 29 males and 16 females with male to female ratio of $2.1: 1$ in group I and with ratio of 1.5:1 in group II. The weight ranges from $7-25 \mathrm{~kg}$ with mean weight of $14.5 \mathrm{~kg}$ in group I and 15.6 in group II. The side distribution was almost equal on both groups i.e. right side was involved in 12 cases and It. side involved in 10 cases in grouplwhereas 11 cases in right side and 12 cases in It. side in group II. The spiral, oblique fracture was most frequent in group I whereas oblique, transverse fracture was most common in group II ( $p$ value-0.377) Fall from height is the commonest mode of injury in both the groups followed by RTA in group II and play injury in group I. Fracture location in middle/3rd followed by upper/3rd is the common site of fracture in both the groups. Hip spica was applied within 1.76 days of injury in group I and within 13.09 days of injury in group II (pvalue-0.000). One and half hip spica was applied most commonly applied in both the groups irrespective of age of the patients and double spica in few cases (infants). The mean days of traction in group II were 12.26. The mean days of hospital stay in group $I$ is 2.36 and 13.04 in group II (pvalue-0.000) the mean initial shortening of fracture 1.21 in group I and 1.23 in group II (pvalue-0.898) the final shortening ( $p$ value0.838 ) and thigh muscle wasting was equal in both the groups ( $p$ value-0.354). The 
complications noted were breakage of hip spica in 9 cases out of which 5 in group I and 4 in group II which was treated with reinforcing of plaster. The other complications were pressure sores in one cases of group I, unacceptable angulations in 0ne cases of group I which was corrected with wedging of cast. There was no complication in terms of distal neurovascular deficit. Angular and rotational control by hip spica was excellent. The maintenance of hygiene was problem in both the groups. The mean radiological union was evident at 9.27 weeks of follow-up in group I and 8.78 weeks in group II (pvalue0.306) there was no difference between the rates of union. Hip spica was removed in all patients in outpatient department.

The protocol of treatment we used has been shown to be simple and effective. Children without other injuries spent a total of 2.36 days in hospital in group I and 13.04 days in group II. Early spica treatment is also successful for children with associated mild head or abdominal injuries although they spend more time in hospital.

The data presented in the current study show that age, as long as the physis is open, is not the only question of importance. The data show size and weight of the patient are key factors. Obviously, the larger the child the more difficult it will be to control the fracture with the hip spica cast and the harder it will be to transport the patient in the hip spica cast. The other significant issue is the socioeconomic impact in the family. Based on radiographic and clinical results current study says that using a well-molded hip spica cast is the gold standard when treating isolated femur fractures in patients with open physes and weight less than $45 \mathrm{~kg}$.

The policy of admitting all children to hospital for reduction of the fracture under general anesthesia allows a short period of observation for other injuries and provides time for the parents to be instructed in the care of their child in a spica. The duration of admission for uncomplicated cases is only one to two days, but it would be possible to reduce the fracture and apply hip spica in the accident and emergency department, as was advocated by Irani et al.The rarity of leg length discrepancy at late review supports previous reports that growth stimulation is directly proportional to the amount of shortening. We found that radiographic shortening when the spica was removed varied from zero to $10 \%$ of femoral length.

Our results allow the definition of criteria for acceptable positions of the fracture during various stages of treatment. At all ages and at all stages of treatment, anterior angulations of less than 20 degrees and angulations of valgus less than 15 degrees are acceptable. Acceptable shortening is related both to the age of the child and the stage of treatment. At the one week review and at the time of 
fracture union the maximum allowable shortening was about $10 \%$ of femoral length at all ages. Greater overlap may have corrected spontaneously, but would hardly be acceptable to the parents at the time of spica removal. It is important to ensure that the parents understand the natural history of recovery. They are often disturbed by the radiographic appearance of a transverse fracture with bayonet apposition and by obvious clinical shortening when the spica is removed. It is necessary to explain that the children are usually stiff and uncomfortable when the spica is removed and will not use the leg for several days, and that even when they start to stand and walk they will have a severe limp due to weakness and shortening. They are told that the child's gait will improve over a few months and the leg length discrepancy will correct over a few years.

\section{Conclusion}

This study shows there is significant advantage in primary hip spica cast for the treatment of isolated, closed femur fractures in children ages less than 10 years and weight less than 80 pounds $(45 \mathrm{~kg})$ which allowed us to treat these fractures without any worry of wound dehiscence, pin site infections, avascular necrosis of the femoral head.

It has substantially reduced the cost of treatment and has freed beds used by other children and it is in accordance with general trend towards shorter hospital admissions. So we feel that weight based, rather than an age based algorithm is a better approach to take when contemplating treatment options for children with femur fractures and open physis. Further studies including a larger sample and a longer period of follow-up is desirable.

\section{References}

1. Louis Solomon, David J. Warwick. Selvadurai Nayayam, Apley's system of Orthopedic And fractures, 8th edition, 700-701

2. Mark R. Brinker, Review of orthopedic trauma, 404- 405

3. Robert W. Bucholz, M.D. James D. heckman, M.D., Rockwood and Green's Fractures in Children, $5^{\text {th }}$ Edi, Volume 2-B, 1683-1690

4. Ferguson, John MB.Ch. B.; Nicol, Early spica treatment of pediatric femoral shaft Fractures $\mathrm{J}$ pediatr Orthop, Volume 20(2). March/ April 2000. 189-192

5. Wilson JN Healing of injury, In: Watson-Jones, Fracture and Joint Injuries. 1982;6(2): 977-993

6. A Paige Whittle; Fractures and dislocations in children's Terry Canale, Editor In: Campbell's 
Operative Orthopedics; $10^{\text {th }} \quad \mathrm{Edi}$, Volume 2-A, 1504-1512

7. Buckley, Steven L. Current Trends in the treatment of femoral shaft fractures in children And Adolescents. 1997;338: 60-73

8. Infante, Anthony F. Jr. DO; Albert, Michael c. MD; Immediate hip spica casting for Femur fractures in pediatric patients: A review of 175 Patients. Clin Orthop. 2000;376: 106112

9. Sugi $M$, ColeWG: early plaster treatment for fractures of the femoral shaft in childhood. J Bone joint Surg 69B: 743-745, 1987.

10. John C Thomson, Editor, In: Netter's Concise Atlas of Orthopedic anatomy, $1^{\text {st }}$ Edi 2002

11. Stans, Anthony AMD; Morrissy, Raymond T.M.D.; Renwick, Stephen E.M.D: Femoral Shaft fracture treatment in patients age 6 to 16 years. J pediatr Orthop. 1999;19(2): 222-228

12. Irani RN, Nicholson JT, Chung MK: Long-term results in the treatment of femoral- shaft Fractures in young children by immediate spica immobilization. J Bone Joint Surg 58A: 945 - 951, 1976.

13. Infante, Anthony F, Albert: Immediate Hip spica casting for femoral shaft fractures in Pediatric patients: A Review of 175 patients, Clin Ortho. 2000;376:106-112

14. Ferguson, John M. B. Ch.B; Nicol: Early spica treatment of pediatric femoral shaft fractures $\mathrm{J}$ Pediatric. 2000;20(2): 189-192

15. James $G$. Wright: The treatment of femoral shaft fractures in children: A systemic Overview and critical appraisal of the literature: CJS. 2000;43(3):181-187. 